\title{
QUESTÃO AGRÁRIA E DESENVOLVIMENTO ECONÔMICO E SOCIAL NAS REGIÕES NORTE E NOROESTE FLUMINENSE ${ }^{1}$
}

\author{
Paulo Marcelo de Souza ${ }^{2}$ \\ Niraldo José Ponciano ${ }^{3}$ \\ Henrique Tomé da Costa Mata ${ }^{4}$ \\ Edenio Detmann ${ }^{5}$
}

Resumo - Esta pesquisa objetivou analisar a evolução da estrutura fundiária e o comportamento dos indicadores de desenvolvimento econômico e social nas regiões norte e noroeste fluminense. Além disso, buscou verificar se a distribuição da terra é uma variável importante na explicação das divergências entre o grau de desenvolvimento econômico dos municípios. Os resultados mostram que, nas regiões em questão, as diferenças na estrutura fundiária, isoladamente, não podem explicar as diferenças no grau de desenvolvimento econômico e social. O tamanho da população, por sua vez, mostrou-se uma variável importante nesse processo, o que pode estar associado ao maior potencial de consumo, que atrai o setor privado, bem como ao poder político, devido ao tamanho do eleitorado, que influencia a destinação dos investimentos públi$\cos$.

Palavras-chave: estrutura fundiária, desenvolvimento econômico e social, royalties.

\footnotetext{
${ }^{1}$ Recebido em 02/08/2004. Aceito em 20/09/2004.

Trabalho apresentado no XLII Congresso da SOBER, Cuiabá - MT, em julho/2004.

${ }^{2}$ Professor associado da Universidade Estadual do Norte Fluminense - UENF, Centro de Ciências e Tecnologias Agropecuárias - CCTA Laboratório de Engenharia Agrícola/Setor de Economia Agrícola Av. Alberto Lamego, 2000 - Parque Califórnia CEP 28013-600 - Campos dos Goytacazes - RJ. E-mail: pmsouza@ uenf.br.

${ }^{3}$ Professor associado da Universidade Estadual do Norte Fluminense - UENF, Centro de Ciências e Tecnologias Agropecuárias - CCTA Laboratório de Engenharia Agrícola/Setor de Economia Agrícola Avenida Alberto Lamego, 2000 28013-600 Campos dos Goytacazes - RJ. E-mail: ponciano@uenf.br.

${ }^{4}$ Professor associado da Universidade Estadual de Santa Cruz - UESC, Departamento de Ciências Econômicas Rod. Ilhéus-Itabuna, km 16, 456650-000, Ilhéus, BA. E-mail:hnrmata@uesc.br.

${ }^{5}$ Universidade Federal de Viçosa - UFV, Centro de Ciências Agrárias, Departamento de Zootecnia. CEP 36570000 Viçosa - MG. E-mail: detmann@ufv.br.
} 


\section{Introdução}

No Brasil, a distribuição da terra é historicamente concentrada, fato cuja origem remonta ao período da colonização, com as capitanias hereditárias e a doação das sesmarias. Tal situação ensejou, no final dos anos 50 e início dos anos 60, o crescimento dos debates e da pressão popular em torno da questão agrária, cuja resolução era percebida como necessária ao crescimento do país, bem como à constituição de uma sociedade menos desigual.

Nesse momento, diante da necessidade de promover a modernização da agricultura, os debates podiam ser agrupados em duas vertentes principais; a modernização estruturalista, que pregava a necessidade de ampla reforma agrária, e a modernização conservadora, segundo a qual a modernização poderia prescindir de alterações na estrutura fundiária. Diferentemente da primeira vertente, para a Segunda, a questão agrária não era essencial à modernização, que poderia avançar sem alterações na estrutura fundiária vigente, além de a exclusão social daí resultante ser enfrentada pelas novas oportunidades criadas fora da agropecuária (Gonçalves, 1999).

Na perspectiva da modernização estruturalista, a manutenção da estrutura agrária brasileira, tradicionalmente concentrada, representaria sério óbice ao desenvolvimento econômico e social do país. Assim, para Guimarães (1982), que via na estrutura agrária brasileira resquícios feudais, o latifúndio representava um instrumento de poder, capaz de assegurar aos latifundiários forças extra-econômicas de dominação sobre os demais agricultores. Nesse sentido, seria necessário eliminar o latifúndio e, por conseguinte, suprimir uma estrutura de dominação que possibilitava a exploração da grande massa de trabalhadores.

Para Prado Jr. (1966), que discordava da hipótese da presença de resquícios feudais na agricultura brasileira, a extensão da propriedade não impediria o desenvolvimento capitalista. Por outro lado, tampouco a expansão das relações capitalistas no campo, que eliminava as relações de 
trabalho arcaicas, seria condição suficiente para elevar o padrão de vida de sua população, sendo esperado que ocorresse exatamente o oposto. Em sua concepção, a grande propriedade não era nociva pelo tamanho, mas sim porque propiciava e garantia condições para grande exploração da maioria dos trabalhadores, aos quais a terra era inacessível.

A assertiva segundo a qual o avanço do progresso técnico nas atividades agrícolas eliminaria, necessariamente, o atraso e a miséria rural é o ponto central atacado por Furtado (1972). Para esse autor, o latifúndio constituía um meio de assegurar à minoria uma oferta elástica de mão-deobra e impor à população certo padrão de distribuição de renda.

Segundo Furtado, a elevação dos custos da mão-de-obra e a redução dos custos dos insumos agrícolas eram condições necessárias para induzir os proprietários à capitalização, incentivando-os a aderir ao progresso técnico. Essas condições inexistiam no Brasil, devido à grande concentração de terra, que garantia uma oferta de mão-de-obra elástica e a baixo custo. A estagnação do nível de vida da população rural, por sua vez, contribuiria para deprimir os salários urbanos, que impediriam a elevação da demanda de produtos agrícolas. Nessa perspectiva, deixar de resolver a questão agrária seria optar por um processo de desenvolvimento que daria origem a uma sociedade com nível de exclusão social crescente.

Para Rangel (1962), o problema agrário brasileiro centralizava-se em duas questões: a superpopulação e a superprodução. A superpopulação decorria da presença de grande massa populacional rural que, submetida às grandes propriedades, tenderia às cidades onde, devido ao fato de as indústrias instaladas serem poupadoras de mão-de-obra, não seria absorvida. Com o êxodo rural, o problema do campo seria apenas transferido para as cidades, onde seria reproduzida a péssima distribuição de renda prevalecente no campo. Já a superprodução decorreria dos ciclos de altas e baixas do mercado internacional, ao qual a agricultura brasileira se encontrava estreitamente vinculada, dada a incapacidade do mercado interno em absorver seus produtos, em razão da insuficiente renda populacional e de sua má distribuição. 
Não obstante essas perspectivas, a opção brasileira foi pela modernização, sem alterações, na estrutura fundiária. Conforme Gonçalves (1999), a modernização, na forma como ela se deu, caracterizou-se como uma pseudomorfose, isto é, transformação sem ruptura, uma modernização com manutenção do poder político. Segundo a abordagem estruturalista, tal processo não resultaria numa industrialização que incorporasse o excedente populacional rural, formando uma economia de altos salários, mas contribuiria para formação de um exército de reserva, obstáculo ao movimento de modernização com distribuição de renda.

Por um lado, pode-se inferir, a partir da leitura desses autores, que a modernização sem alteração na estrutura fundiária ensejaria o surgimento de uma sociedade excludente, baseada nos baixos salários da maioria da população. Neste trabalho, essa perspectiva é utilizada como base para a hipótese de que a estrutura fundiária de determinado município pode ser importante fator explicativo para seu desenvolvimento econômico e social.

Por outro, é necessário considerar a possibilidade de que, além do perfil fundiário - um dos aspectos históricos inerentes à constituição desses municípios e teoricamente indissociável de suas realidades, outros eventos possam atuar, de forma preponderante, no desenvolvimento econômico regional. Dada a complexidade do problema do desenvolvimento, que envolve aspectos como fatores históricos, dotação de recursos, investimento em capital humano, conformação política, etc., fornecer uma explicação razoável das diferenças no grau de desenvolvimento dos municípios em análise é uma tarefa bastante complexa. Para isso, seria necessário enumerar os diversos fatores e eventos que atuaram nesses municípios, conformando distintas estruturas econômicas, políticas e sociais que propiciaram ambientes mais ou menos propícios ao desenvolvimento.

Por essa razão, não se pretende fazer um estudo profundo acerca desses fatores, que seria demasiado complexo e fugiria ao escopo deste trabalho, mas verificar a hipótese de que as diferenças na estrutura 
fundiária possam ser fator de grande relevância. De qualquer modo, tal relação não pode ser aferida quando se desconsidera a presença de eventos de grande importância nos municípios da região, com grande potencial para alterar, em prazo relativamente curto, seus principais indicadores econômicos e sociais, como o é o caso, por exemplo, do advento dos roytalties pagos pela produção de petróleo.

Com cerca de $81 \%$ da produção nacional de petróleo, a Bacia de Campos propicia aos municípios "produtores" a condição de maiores recebedores de royalties e participações especiais do país. Embora os royalties já viessem sendo pagos desde a década de 50, pouco após a fundação da Petrobras, o valor arrecadado beneficiava exclusivamente a União. Até 1985, os royalties cobrados sobre a produção na plataforma continental não beneficiavam estados e municípios confrontantes com campos petrolíferos. Somente ao final de 1985, o pagamento destes royalties estendeu-se também aos municípios, por meio da Lei no. 7.453, de 27 de dezembro de 1985. A partir de 1997, com a aprovação da Lei do Petróleo (Lei 9.478, de 06.08.97), os recursos dos royalties vêm aumentando significativamente, em decorrência da elevação da alíquota ou das novas regras para definição dos valores de referência do petróleo e gás, sobre os quais incidem as alíquotas (Leal e Serra, 2003).

Em razão dessas mudanças, os municípios beneficiados com os recursos da atividade petrolífera têm, em relação aos demais, maiores possibilidades de alavancarem seu desenvolvimento. Desse modo, além da hipótese de que diferenças no grau de concentração fundiária entre regiões implicariam também diferenças nos seus indicadores de desenvolvimento, inclui-se ainda a hipótese de que essas diferenças estariam também associadas ao recebimento, ou não, dos royalties. Essa perspectiva de análise é utilizada no estudo do caso particular das regiões norte e noroeste do estado do Rio de Janeiro, nitidamente distintas no que diz respeito ao perfil fundiário, cujos municípios se apresentam bastante diversos nos indicadores de desenvolvimento econômico e social. 


\section{Objetivos}

A pesquisa busca, num primeiro momento, descrever a estrutura fundiária e os indicadores de desenvolvimento econômico e social dos municípios das regiões norte e noroeste fluminense. Caracterizadas as diferenças entre estrutura fundiária e grau de desenvolvimento, procura-se verificar a relação entre esses parâmetros.

\section{Metodologia}

\subsection{Caracterização da estrutura fundiária e do grau de desenvol- vimento econômico e social}

Para analisar as alterações na estrutura fundiária, foram calculados o índice de Gini, a área média, o percentual da área correspondente aos $50 \%$ menores imóveis e o percentual correspondente aos 5\% maiores imóveis, que, normalmente, são usados como indicadores da distribuição da posse da terra.

A descrição do grau de desenvolvimento econômico e social dos diversos municípios foi realizada com base no Índice de Desenvolvimento Humano (IDH), no Índice de Desenvolvimento Socioeconômico (ISE), no Índice de Qualidade dos Municípios (IDH-M) e no Índice de Qualidade dos Municípios-Carências (IQM-Carências).

Criado pela ONU no início dos anos 90, o Índice de Desenvolvimento Humano (IDH) inclui, além da variável renda, geralmente empregada como indicador do grau de desenvolvimento, um conjunto de outras variáveis capazes de captar diversos aspectos das condições de vida da população. Em termos agregados, compõe-se de três índices, ou seja, longevidade (esperança de vida ao nascer), educação (número médio de anos de estudo e taxa de analfabetismo) e renda (renda familiar per capita média ajustada), os quais participam, com iguais pesos, na composição do índice final. De modo semelhante ao IDH, o IDH municipal é 
um índice que mede o desenvolvimento humano por unidade geográfica, obtido de metodologia semelhante ao primeiro, porém introduzindo algumas adaptações metodológicas e conceituais necessárias para torná-lo aplicável aos municípios.

O Índice de Qualidade dos Municípios (IQM), criado em 1998, é elaborado pela fundação CIDE para avaliar os municípios, no intuito de aferir a existência de condições para atrair investimentos, assim como a capacidade de geração de efeitos multiplicados dos investimentos realizados. Esse índice é composto de sete indicadores (centralidade e vantagem locacional, qualificação de mão-de-obra, riqueza e potencial de consumo, facilidades para negócios, infra-estrutura para grandes empreendimentos, dinamismo da economia local e cidadania), que participam com diferentes pesos, os quais envolvem aspectos admitidos como necessários à realização de investimentos nos municípios.

O IQM-Carências é um índice formatado a partir de um conjunto de indicadores escolhidos, com o objetivo de demonstrar o nível de carência da população de cada município do estado do Rio de Janeiro. O conceito de carências neste IQM emergiu dos princípios constitucionais e dos direitos sociais dispostos na Constituição de 1988, em cujos artigos se encontram estabelecidos os direitos sociais da população (educação, saúde, trabalho, lazer, segurança, previdência social, proteção à maternidade e à infância e assistência aos desamparados) e suas necessidades vitais básicas (moradia, alimentação, educação, saúde, lazer, vestuário, higiene, transporte e previdência social). Na criação desse índice foram considerados os atributos inerentes tanto aos indivíduos quanto aos lugares, ampliando-se o conceito de desenvolvimento social. Introduziramse, além dos temas tradicionais (educação, saúde, habitação, saneamento e renda), outros novos (segurança, mercado de trabalho, esporte, cultura, lazer e participação comunitária), assim como aqueles associados às novas exigências impostas pelo processo de globalização e reestruturação produtiva em curso, levando-se em conta, além da questão da cidadania, questões referentes à tecnologia, às vantagens/oportunidades locacionais, à comunicação e ao transporte. 


\subsection{Análise de regressão}

Para verificar o efeito das diferenças no grau de concentração fundiária e das alterações na distribuição da posse da terra sobre os indicadores de desenvolvimento econômico e social dos municípios, foram estimadas quatro equações, cada qual pertinente a um dos indicadores de desenvolvimento utilizados, e cuja forma funcional é a seguinte:

$$
Y_{i}=\beta_{0}+\lambda_{01} R G_{1 i}+\lambda_{02} R Y_{2 i}+\beta_{1} I_{i}+\beta_{2} A_{i}+\beta_{3} A 5_{i}+\beta_{4} A 50_{i}+\beta_{5} P P_{i}+e_{i},
$$

em que, para cada município i, Y é o indicador utilizado, ou seja, o índice de desenvolvimento humano (IDH), o índice de qualidade municipal (IQM), o índice de qualidade municipal-carências (IQM-carências) ou o índice socioeconômico (ISE); IG, índice de Gini; AM, área média, em ha; A5, percentual da área correspondente aos 5\% maiores estabelecimentos; A50, percentual da área correspondente aos 50\% menores estabelecimentos; POP, população do município, em número de habitantes ${ }^{6}$; e, termo de erro aleatório. O modelo incluiu também as seguintes variáveis dummies, para captar o efeito da região e do recebimento de royalties sobre os parâmetros das equações, em que REG $=1$, para os municípios da região norte e 0 , para os municípios da região noroeste; ROY $=1$, para municípios que participam da Organização dos Municípios Produtores de Petróleo da Bacia de Campos-OMPETRO (Campos, Macaé, Quissamã, São João da Barra e Carapebus) e 0, para os demais. Na função do IDH, foi considerado o ano de $1991 \mathrm{em}$ todos as variáveis. No caso dos demais índices, os indicadores relativos à distribuição da terra e da população foram os do ano de 1998. Para estimar a equação, foi empregado o método dos mínimos quadrados ponderados.

\footnotetext{
${ }^{6}$ A inclusão da variável população baseia-se na observação de Totti et al. (2002), que constataram que melhores índices de qualidade de vida eram encontrados nos municípios de maior população.
} 


\subsection{Variáveis e fonte de dados}

As informações necessárias ao cômputo dos indicadores da distribuição da terra, relativas à área correspondente a cada estrato de tamanho de imóvel, foram obtidas das Estatísticas Cadastrais e das Estatísticas Cadastrais Anuais do INCRA. Mais especificamente, foram computados os dados das Estatísticas Cadastrais de 1998, assim como das Estatísticas Cadastrais anuais de 1991.

As informações sobre o Índice de Desenvolvimento Humano Municipal, elaborado pelo Instituto de Pesquisa Econômica Aplicada - IPEA, Fundação João Pinheiro do Governo do Estado de Minas Gerais - FJP/MG e Programa das Nações Unidas para o Desenvolvimento- PNUD, foram obtidas nas publicações do Tribunal de Contas do Estado do Rio de Janeiro-TCE. Quanto ao Índice de Desenvolvimento Socioeconômico (ISE), sua metodologia de cálculo e os valores obtidos encontram-se em Totti et al. (2002). Já o Índice de Qualidade dos Municípios (IDH-M) e o Índice de Qualidade dos Municípios-Carências (IQM-Carências) foram obtidos na Fundação CIDE - Centro de Informações e Dados do Rio de Janeiro, responsável pela elaboração destes.

\section{Resultados e discussão}

\subsection{Indicadores da distribuição da terra}

A Tabela 1 exibe os valores do índice de Gini da distribuição da posse da terra para os municípios das regiões norte e noroeste fluminense. Podese constatar que, de modo geral, esse indicador é mais elevado nos municípios pertencentes à região norte, com destaque para os municípios de Campos dos Goytacazes, onde ele se situa próximo de 0,800, e também Macaé, Quissamã e São João da Barra, cujos índices de Gini se situam, em geral, na faixa de 0,700 a 0,750 . Apesar disso, tomando-se os valores 
calculados por Hoffmann (1988), para o ano de 1998, pode-se concluir que a distribuição da terra nesses municípios é menos concentrada do que a do Brasil, cujo índice de Gini é de 0,843 , e, com exceção de Campos dos Goytacazes, apresenta-se semelhante à distribuição da região Sudeste, cujo índice é de 0,757, e do Rio de Janeiro, que é de 0,751. 
Paulo Marcelo de Souza, Niraldo José Ponciano,

Henrique Tomé da Costa Mata \& Edenio Detmann

Tabela 1 - Índice de Gini (IG), área média (AM), percentual da área correspondente aos 5\% maiores estabelecimentos (A5) e percentual correspondente aos $50 \%$ menores (A50) da distribuição da posse da terra nos municípios das regiões norte e noroeste fluminense, 1991 e 1998

\begin{tabular}{|c|c|c|c|c|c|c|c|c|}
\hline \multirow{2}{*}{ Região/Município } & \multicolumn{2}{|c|}{ IG } & \multicolumn{2}{|c|}{$\mathrm{AM}$} & \multicolumn{2}{|c|}{ A5 } & \multicolumn{2}{|c|}{ A50 } \\
\hline & 1991 & 1998 & 1991 & 1998 & 1991 & 1998 & 1991 & 1998 \\
\hline \multicolumn{9}{|l|}{ Norte } \\
\hline C.dos Goytacazes & 0,79 & 0,79 & 40,22 & 46,31 & 58,04 & 57,24 & 4,39 & 4,22 \\
\hline Cardoso Moreira & - & 0,76 & - & 50,31 & - & 59,42 & - & 7,53 \\
\hline Conceição de Macabu & 0,66 & 0,66 & 107,13 & 114,77 & 39,68 & 36,63 & 8,53 & 7,26 \\
\hline Macaé & 0,72 & 0,73 & 67,51 & 75,89 & 48,13 & 48,89 & 7,95 & 7,29 \\
\hline Quissamã & 0,75 & 0,77 & 83,51 & 66,11 & 43,75 & 47,48 & 4,36 & 3,65 \\
\hline São João da Barra & 0,73 & 0,72 & 26,99 & 27,61 & 51,97 & 50,94 & 7,12 & 7,32 \\
\hline São Fidélis & 0,65 & 0,65 & 36,84 & 33,71 & 41,79 & 42,72 & 11,69 & 11,77 \\
\hline \multicolumn{9}{|l|}{ Noroeste } \\
\hline Aperibé & - & 0,39 & - & 7,50 & - & 9,97 & - & 18,44 \\
\hline B. Jesus do Itabapoana & 0,60 & 0,58 & 52,22 & 50,73 & 36,43 & 30,75 & 11,83 & 12,49 \\
\hline Cambuci & 0,65 & 0,64 & 43,11 & 44,11 & 38,64 & 38,76 & 10,25 & 10,75 \\
\hline Italva & 0,62 & 0,64 & 32,00 & 31,86 & 40,72 & 43,58 & 12,67 & 12,49 \\
\hline Itaocara & 0,63 & 0,69 & 23,63 & 32,05 & 39,84 & 48,30 & 10,98 & 9,22 \\
\hline Itaperuna & 0,64 & 0,66 & 55,98 & 65,81 & 39,63 & 41,63 & 9,95 & 9,47 \\
\hline Laje do Muriaé & 0,62 & 0,65 & 56,30 & 50,44 & 35,57 & 36,86 & 11,11 & 9,68 \\
\hline Miracema & 0,61 & 0,64 & 54,38 & 57,02 & 29,70 & 30,36 & 9,54 & 8,57 \\
\hline Natividade & 0,60 & 0,61 & 54,02 & 46,89 & 31,40 & 31,90 & 10,94 & 10,96 \\
\hline Porciúncula & 0,60 & 0,58 & 57,58 & 59,14 & 30,11 & 30,38 & 10,35 & 12,35 \\
\hline Sto. Antônio de Pádua & 0,59 & 0,58 & 28,74 & 29,90 & 33,33 & 32,30 & 13,72 & 13,78 \\
\hline Varre-Sai & - & 0,54 & - & 45,85 & - & 25,21 & - & 13,6 \\
\hline
\end{tabular}

Fonte: Dados da pesquisa. 
Com relação à área média dos imóveis, pode-se observar que esse indicador é mais elevado no município de Conceição de Macabú, onde o valor é superior a 100 hectares, assim como em Quissamã e Macaé, onde a área média está compreendida, na maior parte do período, na faixa de 65 a 85 hectares. Já os municípios de Italva, Itaocara, Santo Antônio de Pádua, São Fidélis e São João da Barra se destacam entre os demais, por apresentarem as menores áreas médias, que se situam, durante o período estudado, na faixa de 20 a 40 hectares. Em situação intermediária estão todos os demais municípios, que têm área média de 40 a 60 hectares.

Pode-se constatar que o percentual da área total correspondente aos $5 \%$ maiores imóveis é elevado, visto que se situa próximo de $60 \%$, nos municípios de Campos dos Goytacazes e Cardoso Moreira, embora neste último caso essa constatação se refira apenas ao ano de 1998. Esse percentual é também elevado, da ordem de 50\%, nos municípios de São João da Barra e Macaé, o que, no último ano, também se aplica a Quissamã. $\mathrm{O}$ fato de que esses municípios pertencerem à região norte revela, novamente, a diferença marcante entre as estruturas fundiárias dessas regiões. Nos demais municípios, o percentual da área total correspondente aos 5\% maiores imóveis encontra-se na faixa de 30 a $40 \%$.

Observa-se, ainda, que o percentual da área total correspondente aos 50\% menores imóveis é, em geral, muito baixo, não chegando a representar sequer $14 \%$ da área total dos imóveis. Em Campos dos Goytacazes e Quissamã, os 50\% menores imóveis ocupam cerca de apenas 4\% da área total. Em São João da Barra, Macaé e Cardoso Moreira, esse percentual está abaixo do obtido na maioria dos demais municípios, resultado que reflete o perfil fundiário tipicamente mais concentrado dessa região.

Finalizando esse item, a Figura 1, relativa ao ano de 1998, permite visualizar as diferenças entre as duas mesorregiões consideradas. Nela, pode-se observar que valores mais baixos do índice de Gini encontram-se nos municípios da região noroeste, que são, em geral, menores que 0,650, com exceção de Itaperuna e Itaocara, cujos índices de Gini estão na faixa de 0,65 a 0,70. 


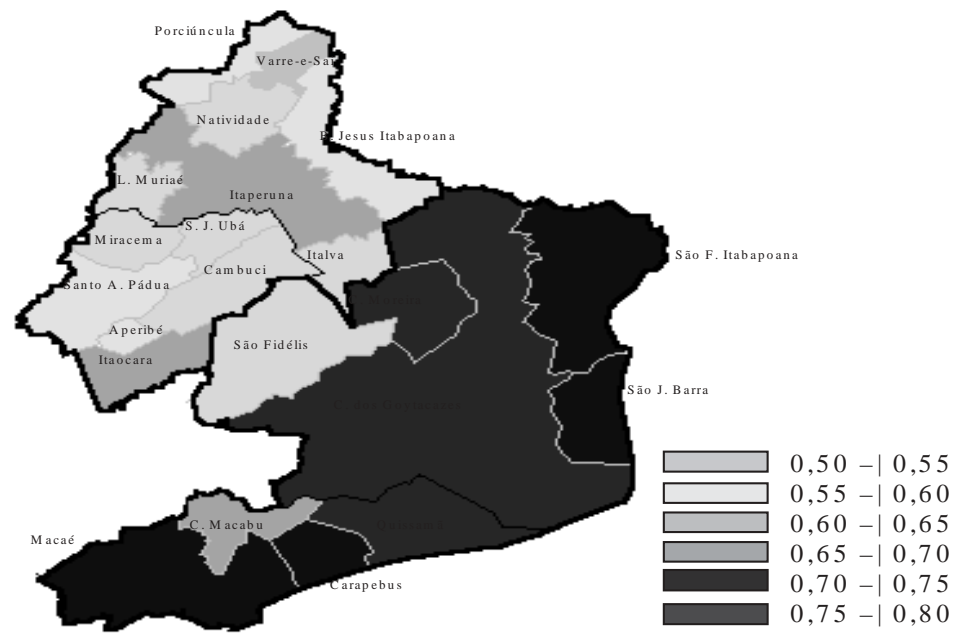

Figura 1 - Índice de Gini da distribuição da posse da terra nas regiões norte e noroeste fluminense, 1998.

Fonte: Tabela 1.

4.2. Indicadores de desenvolvimento econômico e social

A Tabela 2 exibe os valores do índice de desenvolvimento humano para os municípios das regiões norte e noroeste, nos anos de 1970, 1980 e 1991. 
Tabela 2 - Índice de desenvolvimento humano municipal (IDH-M) das regiões norte e noroeste fluminense, 1970, 1980 e 1991

\begin{tabular}{|c|c|c|c|}
\hline Região/Município & 1970 & 1980 & 1991 \\
\hline \multicolumn{4}{|l|}{ Norte } \\
\hline Campos dos Goytacazes & 0,611 & 0,641 & 0,686 \\
\hline Carapebus & - & - & - \\
\hline Cardoso Moreira & - & - & - \\
\hline Conceição de Macabu & 0,644 & 0,595 & 0,612 \\
\hline Macaé & 0,63 & 0,69 & 0,755 \\
\hline Quissamã & - & - & 0,571 \\
\hline S. João da Barra & 0,561 & 0,442 & 0,522 \\
\hline São F. de Itabapoana & - & - & - \\
\hline São Fidélis & 0,621 & 0,53 & 0,61 \\
\hline \multicolumn{4}{|l|}{ Noroeste } \\
\hline Aperibé & - & - & - \\
\hline B. Jesus do Itabapoana & 0,473 & 0,632 & 0,612 \\
\hline Cambuci & 0,469 & 0,517 & 0,610 \\
\hline Italva & - & - & 0,591 \\
\hline Itaocara & 0,642 & 0,609 & 0,641 \\
\hline Itaperuna & 0,439 & 0,637 & 0,724 \\
\hline Laje do Muriaé & 0,393 & 0,488 & 0,539 \\
\hline Miracema & 0,585 & 0,604 & 0,624 \\
\hline Natividade & 0,447 & 0,589 & 0,599 \\
\hline Porciúncula & 0,469 & 0,581 & 0,624 \\
\hline S. José de Ubá & - & - & - \\
\hline Santo Antônio de Pádua & 0,547 & 0,614 & 0,664 \\
\hline Varre-Sai & - & - & - \\
\hline
\end{tabular}

Fonte: IPEA/FJP/IBGE/PNUD e Relatório das Contas de Gestão do Governador -Exercício 1999-TCE-RJ. 
Na Figura 2, que exibe a evolução do Índice de Desenvolvimento Humano dos municípios, de 1970 a 1991, pode-se constatar que a maior parte dos municípios experimenta persistente elevação desse índice ao longo de todo período. As exceções são Conceição de Macabu, Itaocara, São Fidélis e São João da Barra, nos quais o IDH declina entre 1970 e 1980, para voltar a elevar em 1991, e Bom Jesus do Itabapoana, onde esse índice apresenta pequena redução no ano de 1991, em relação ao ano de 1980. Dentre os municípios cujo IDH sofreu elevação no período, destacam-se os de Cambuci, Itaperuna, Laje do Muriaé, Macaé, Natividade, Porciúncula e Santo Antônio de Pádua.

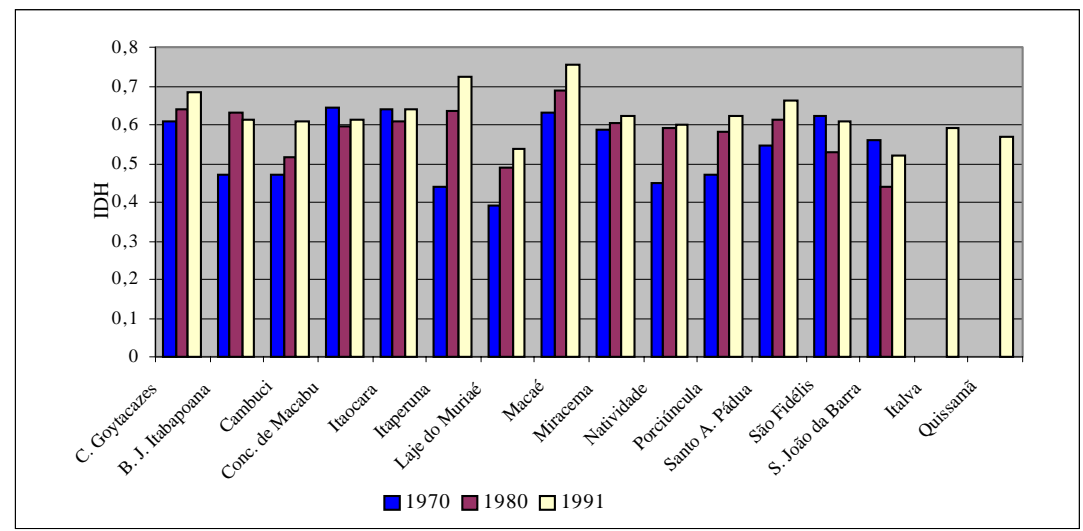

Figura 2 - Evolução do índice de desenvolvimento humano dos municípios das regiões norte e noroeste fluminense.

Fonte: Tabela 2.

Em decorrência da evolução apresentada, ocorreram mudanças na posição relativa dos municípios, no que concerne ao índice de desenvolvimento humano, como pode ser constatado na Tabela 3. No ano de 1970, os cinco municípios com melhores índices foram Conceição de Macabu, Itaocara, Macaé, São Fidélis e Campos dos Goytacazes. Em 1980, Macaé, Campos dos Goytacazes, Itaperuna, Bom Jesus do Itabapoana e Santo Antônio de Pádua ocuparam, nessa ordem, os cinco primeiros lugares no ranking do IDH. Em 1991, maiores índices são apresentados, em ordem decrescente de importância, por Macaé, Itaperuna, Campos dos 
Goytacazes, Santo Antônio de Pádua e Itaocara. Nesse processo, há que se destacar a liderança de Macaé e o crescimento do Índice de Desenvolvimento Humano de Itaperuna, que, de município retardatário em 1970, passa a ocupar, em 1991, a posição de segundo lugar no ranking dos municípios das regiões norte e noroeste fluminense.

Tabela 3 - Classificação dos municípios das regiões norte e noroeste fluminense, segundo os valores do índice de desenvolvimento humano municipal, 1970, 1980 e 1991

\begin{tabular}{cccc}
\hline \multirow{2}{*}{ Posição } & & \multicolumn{3}{c}{ Ano } & \\
\cline { 2 - 4 } & Conceição de Macabu & Macaé & Macaé \\
\hline 1 & Itaocara & Campos dos Goytacazes & Itaperuna \\
3 & Macaé & Itaperuna & Campos dos Goytacazes \\
4 & São Fidélis & B. Jesus do Itabapoana & Santo Antônio de Pádua \\
5 & Campos dos Goytacazes & Santo Antônio de Pádua & Itaocara \\
6 & Miracema & Itaocara & Miracema \\
7 & S. João da Barra & Miracema & Porciúncula \\
8 & Santo Antônio de Pádua & Conceição de Macabu & B. Jesus do Itabapoana \\
9 & B. Jesus do Itabapoana & Natividade & Conceição de Macabu \\
10 & Cambuci & Porciúncula & Cambuci \\
11 & Porciúncula & São Fidélis & São Fidélis \\
12 & Natividade & Cambuci & Natividade \\
13 & Itaperuna & Laje do Muriaé & Italva \\
14 & Laje do Muriaé & S. João da Barra & Quissamã (Macaé) \\
15 & - & - & Laje do Muriaé \\
16 & - & S. João da Barra \\
\hline
\end{tabular}

Fonte: Tabela 2. 
A Tabela 4 exibe, para os municípios das regiões norte e noroeste fluminense, os valores dos demais índices considerados na análise, ou seja, o índice socioeconômico (ISE), o de qualidade dos municípios (IQM) e o de qualidade municipal-carências (IQM-carências). As Figuras 3, 4 e 5, elaboradas a partir das informações dessa tabela, permitem verificar a posição de cada município com relação aos valores desses índices.

Tabela 4 - Índice socioeconômico (ISE), índice de qualidade municipal (IQM) e índice de qualidade municipal-carências (IQM-carências) dos municípios(IQM) das regiões norte e noroeste fluminense

\begin{tabular}{|c|c|c|c|}
\hline Região/Município & ISE $^{1}$ & $\mathrm{IQM}^{2}$ & IQM-Carências $^{3}$ \\
\hline \multicolumn{4}{|l|}{ Norte } \\
\hline Campos dos Goytacazes & 6,940 & 0,369 & 42,30 \\
\hline Carapebus & 4,510 & 0,147 & 62,50 \\
\hline Cardoso Moreira & 2,990 & 0,094 & 63,30 \\
\hline Conceição de Macabu & 4,420 & 0,182 & 57,30 \\
\hline Macaé & 8,280 & 0,468 & 41,90 \\
\hline Quissamã & 5,420 & 0,192 & 57,40 \\
\hline S. João da Barra & 6,130 & 0,154 & 52,40 \\
\hline São F. de Itabapoana & 2,860 & 0,000 & 60,60 \\
\hline São Fidélis & 5,070 & 0,153 & 51,50 \\
\hline \multicolumn{4}{|l|}{ Noroeste } \\
\hline Aperibé & 4,840 & 0,214 & 58,50 \\
\hline B. Jesus do Itabapoana & 6,200 & 0,303 & 51,20 \\
\hline Cambuci & 3,900 & 0,165 & 57,40 \\
\hline Italva & 5,080 & 0,160 & 54,80 \\
\hline Itaocara & 5,530 & 0,223 & 53,60 \\
\hline Itaperuna & 7,250 & 0,252 & 46,30 \\
\hline Laje do Muriaé & 3,100 & 0,108 & 61,40 \\
\hline Miracema & 4,640 & 0,279 & 52,30 \\
\hline Natividade & 3,740 & 0,166 & 57,70 \\
\hline Porciúncula & 3,560 & 0,188 & 56,90 \\
\hline S. José de Ubá & 3,060 & 0,025 & 63,90 \\
\hline Santo Antônio de Pádua & 5,920 & 0,348 & 51,20 \\
\hline Varre-Sai & 2,840 & 0,058 & 62,50 \\
\hline
\end{tabular}

Fonte: 1 Totti et al. (2002); 2 CIDE - 1998; 3 CIDE (2001). 
Na Figura 3, que apresenta o índice de qualidade dos municípios das regiões norte e noroeste, pode-se constatar que os melhores indicadores estão nos municípios de Macaé e, em seguida, nos de Campos dos Goytacazes e Santo Antônio de Pádua, com destaque para Bom Jesus do Itabapoana, Miracema e Itaperuna. Os municípios de São José de Ubá e Varre-Sai apresentaram índices bem inferiores, e os de Cardoso Moreira e Laje do Muriaé, os piores índices.

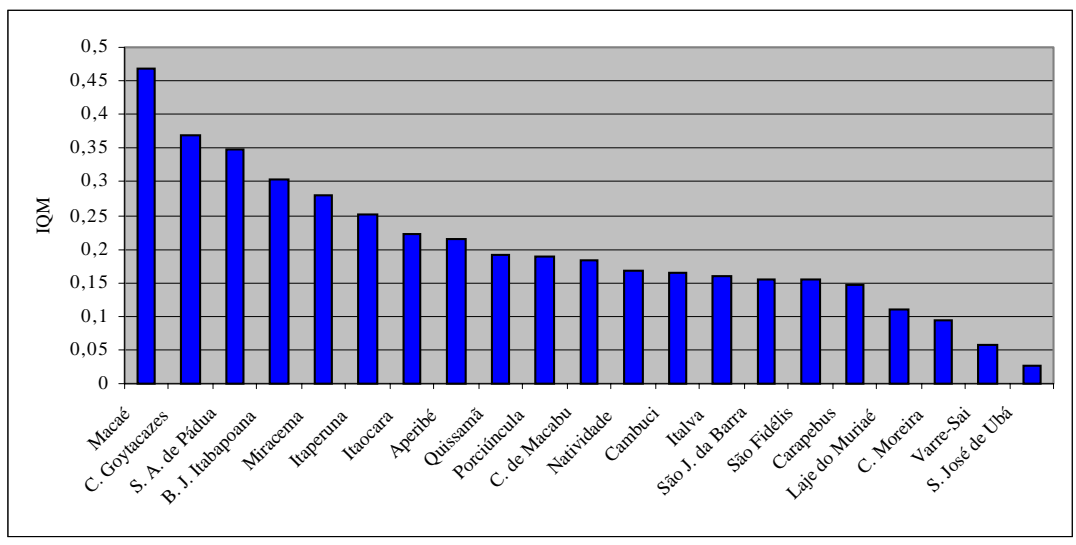

Figura 3 - Índice de qualidade dos municípios das regiões norte e noroeste fluminense.

Fonte: Tabela 4.

A posição dos municípios, com relação aos valores do IQM-carências, pode ser apreendida na Figura 4, na qual se verifica que os maiores níveis de carências estão nos municípios de São José de Ubá, Cardoso Moreira, Varre-Sai, Carapebus, Laje do Muriaé e São Francisco de Itabapona. Em situação oposta, com níveis menores de carências, encontram-se os municípios de Bom Jesus do Itabapoana, Campos dos Goytacazes e Macaé, ficando os demais em situação intermediária. 


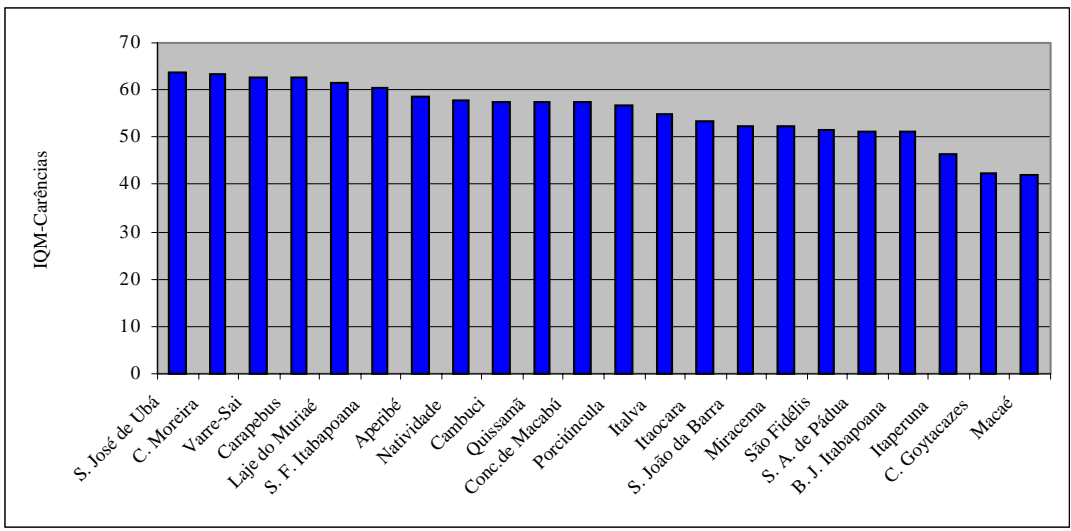

Figura 4 - Índice de qualidade municipal-carências dos municípios das regiões norte e noroeste fluminense.

Fonte: Tabela 4.

A Figura 5, que apresenta os valores do índice socioeconômico, permite concluir que os maiores índices são encontrados nos municípios de Macaé, Itaperuna e Campos de Goytacazes, merecendo ainda destacar Bom Jesus do Itabapoana, São João da Barra e Santo Antônio de Pádua.

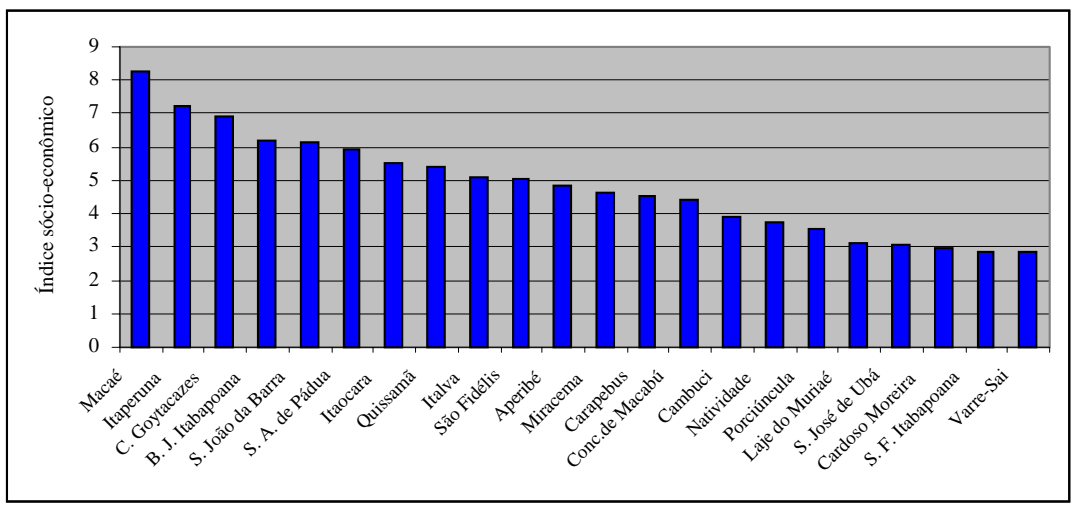

Figura 5 - Índice socioeconômico dos municípios das regiões norte e noroeste fluminense.

Fonte: Tabela 4. 
Por outro lado, os piores indicadores foram encontrados nos municípios de Laje do Muriaé, São José de Ubá, Cardoso Moreira e Varre-Sai, ficando em posição intermediária todos os demais municípios.

\subsection{Análise de regressão}

A Tabela 5 apresenta os resultados das regressões estimadas para os quatro índices de desenvolvimento empregados. Com relação ao índice de desenvolvimento humano, observa-se que este se encontra negativamente relacionado com o percentual da área correspondente aos 5\% maiores estabelecimentos, e positivamente associado ao percentual da área equivalente aos 50\% menores. Porém, exibe relação positiva com a área média dos estabelecimentos, o que é, a princípio, uma relação contrária à esperada. Esses resultados permitem também concluir que maiores valores do índice de desenvolvimento humano encontram-se nos municípios de maior contingente populacional.

É interessante ainda observar que as variáveis binárias, relativas ao recebimento de royalties e à região, mostraram-se negativamente relacionadas com o índice de desenvolvimento humano, evidenciando, em média, níveis menores para esse indicador na região norte e nos municípios beneficiados com receitas do petróleo. 
Tabela 5 - Resultados das regressões lineares estimadas para cada um dos índices de desenvolvimento utilizados

\begin{tabular}{ccccccccccc}
\hline Índice & CONS & IG & AM & A5 & A50 & POP & ROY & REG & R2 & F \\
\hline \multirow{2}{*}{ IDH } & $0,606^{* *}$ & 0,001 & $0,002^{* *}$ & $-0,004^{* *}$ & $0,000^{* *}$ & $0,0064^{* *}$ & $-0,129^{*}$ & $-0,072^{*}$ & 0,995 & $484,825^{* *}$ \\
& $(8,489)$ & $(1,419)$ & $(3,380)$ & $(-5,014)$ & $(8,697)$ & $(7,948)$ & $(-2,509)$ & $(-2,766)$ & & \\
& & & & & & & & & & \\
ISE & $11,350^{*}$ & $-15,041^{*}$ & & $0,101^{* *}$ & $-0,091$ & $0,002^{* *}$ & $1,109^{* *}$ & & 0,999 & $7411,594^{* *}$ \\
& $(2,490)$ & $(-2,081)$ & & $(3,264)$ & $(-0,821)$ & $(8,952)$ & $(7,262)$ & & & \\
& & & & & & & & & & \\
IQM & $1,102^{* *}$ & $-0,867^{* *}$ & $-0,001^{* *}$ & & $-0,031^{* *}$ & $0,000^{* *}$ & $-0,063$ & $0,032^{*}$ & 0,995 & $609,257^{* *}$ \\
& $(4,360)$ & $(-3,747)$ & $(-3,160)$ & & $(-3,672)$ & $(9,573)$ & $(-1,900)$ & $(2,184)$ & & \\
& & & & & & & & & & \\
IQMC & $59,610^{* *}$ & & $0,021^{* *}$ & $-0,123^{* *}$ & & $-0,009^{* *}$ & $-1,230^{* *}$ & & 0,999 & $67697,97 * *$ \\
& $(3,919)$ & & $(5,248)$ & $(-3,645)$ & & $(-4,907)$ & $(-3,275)$ & & & \\
\hline
\end{tabular}

Nota: o valor da estatística t encontra-se entre parênteses; os valores significativos deste teste, a $5 \%$ e $1 \%$ de probabilidade, estão representados por um e dois asteriscos, respectivamente.

Fonte: Dados da pesquisa.

O índice socioeconômico encontra-se negativamente correlacionado com os valores do índice de Gini, mas negativamente associado ao percentual da área correspondente aos 5\% maiores estabelecimentos. Exibe, além disso, relação positiva com o tamanho da população e mostra-se, em média, mais elevado nos municípios participantes da OMPETRO do que nos demais.

O índice de qualidade municipal exibe relação negativa entre o índice de Gini e a área média, sendo, portanto, menor nos municípios de maior concentração fundiária, encontrando-se, porém, negativamente associado ao percentual da área correspondente aos $50 \%$ menores estabelecimentos. Enquanto o recebimento de royalties não mostra relação significativa com esse indicador, ele se encontra positivamente associado ao número de habitantes, sendo, além disso, em média, mais elevado nos municípios da região norte do que nos da noroeste.

Já o índice de carências está positivamente associado ao tamanho da área média e negativamente correlacionado com o percentual da área 
correspondente aos 5\% maiores estabelecimentos. Além disso, pode-se concluir, pelos coeficientes estimados, que menores índices de carências são observados em municípios de maior população, bem como naqueles beneficiados com as receitas da atividade petrolífera.

Constata-se, portanto, que os resultados não são conclusivos quanto à relação entre a estrutura fundiária e os indicadores de desenvolvimento econômico e social, dada a não-significância dos coeficientes estimados e seus sentidos contraditórios, obtidos em alguns casos. Tal fato não pode ser interpretado como evidência contrária das conseqüências indesejáveis da concentração fundiária, visto que, como regra geral, os municípios das regiões estudadas apresentam baixos índices de desenvolvimento, o que permite situá-las como as mais atrasadas do estado. Por outro lado, a análise comparativa entre municípios evidencia que outros fatores podem ter atuado no período, entre os quais a atuação do poder público, o que permite que alguns desses municípios consigam, independentemente de aspectos estruturais, como a questão agrária, alcançar índices de desenvolvimento mais favoráveis.

Além disso, não houve evidência de que o recebimento de royalties seja, para todos os casos, um fator tão determinante dos indicadores utilizados, visto que ora era não-significativo, ora apresentava sinal contrário ao esperado. Uma das possíveis razões refere-se ao mal uso dos recursos, já que, segundo Sampaio (2004), enquanto alguns municípios vêm aproveitando as receitas advindas do petróleo para se desenvolver, em outros não há evidências de progresso associado ao uso dos royalties. Além disso, há de se considerar que os recursos disponibilizados aos municípios como resultado dos royalties, conquanto existentes a partir da segunda metade dos anos 80, somente atingiram maior vulto a partir do final dos anos 90, como reflexo da Lei do Petróleo. É por essa razão que, como ressaltado por Leal e Serra (2003), o IDH-M, calculado a partir de dados do censo de 2000, não estaria captando mudanças significativas nos indicadores de qualidade de vida dos municípios beneficiários de royalties, mormente naqueles que requerem maior prazo de maturação. 
Finalmente, o tamanho da população foi, em todas as situações, um fator importante, sempre correlacionado com as melhores indicadores de desenvolvimento. Uma das explicações para esse resultado é, provavelmente, a existência de um mercado consumidor mais amplo, que atrai maiores investimentos do setor privado, com possíveis efeitos multiplicadores sobre a renda e sobre outros investimentos revertidos em melhoria das condições de vida da população. Outro fator, não menos importante, refere-se ao poder político dos municípios maiores, decorrente do número de eleitores que representam e suas implicações no destino dos investimentos públicos. Certamente, a aprovação de projetos de investimento e a realização de obras voltadas para a melhoria das condições de vida da população, nessas localidades, implicariam dividendos políticos bem mais elevados do que nas cidades menos populosas, o que representaria um importante fator a explicar as diferenças nos índices de desenvolvimento entre os municípios.

\section{Conclusões}

Nesta pesquisa, procurou-se caracterizar o perfil fundiário e o nível de desenvolvimento econômico e social dos municípios das regiões norte e noroeste fluminense, bem como analisar a relação entre esses indicadores. Os resultados permitiram constatar a presença de diferenças significativas entre o perfil agrário dessas regiões e o dos municípios da região norte, destacando-se por uma distribuição nitidamente mais concentrada do que os da região noroeste.

No que diz respeito aos indicadores de desenvolvimento utilizados, constatou-se que, de modo geral, os melhores são encontrados nos municípios de Macaé, Campos dos Goytacazes, Itaperuna, Bom Jesus do Itabapoana e Santo Antônio de Pádua. Na maior parte dos casos, os piores indicadores foram os dos municípios de Laje do Muriaé, São José de Ubá, Cardoso Moreira, Varre-Sai e São João da Barra. O fato de entre os municípios que apresentaram os melhores indicadores constarem Macaé e Campos, que se destacam pela elevada concentração 
fundiária, evidencia que este fator, isoladamente, não pode explicar as diferenças regionais quanto ao grau de desenvolvimento econômico e social.

O recebimento de royalties, admitido como uma das variáveis explicativas das diferenças entre municípios, tampouco mostrou relação inequívoca com os indicadores considerados, o que pode estar refletindo o mau uso dos recursos, não aplicados na promoção do desenvolvimento regional, ou, simplesmente, o pouco tempo desde o início do recebimento desses recursos e a elaboração dos indicadores utilizados.

Finalmente, constatou-se relação positiva entre tamanho da população e indicadores de desenvolvimento. Essa relação se explica, provavelmente, pela maior amplitude do mercado consumidor, que atrai investimentos que geram encadeamentos diversos e contribuem para elevação da renda e das condições de vida da população. Outra explicação encontra-se no maior poder político que o maior número de número de eleitores representa, fato que tende a ter grande influência no destino dos investimentos públicos.

\section{Referências bibliográficas}

FURTADO, C. Estrutura agrária no subdesenvolvimento brasileiro. In.: FURTADO, C. Análise do modelo brasileiro. Rio de Janeiro: Nacional, 1972. p. 89-122.

GONÇALVES, J. S. Mudar para manter: pseudomorfose da agricultura brasileira. São Paulo: CSPA/SAA, 1999. 373p.

GUIMARÃES, A. P. Quatro séculos de latifúndio. São Paulo:Paz e Terra, 1982, 255p. 
HOFFMANN, R. A estrutura fundiária no Brasil de acordo com o cadastro do INCRA: 1967 a 1998. Convênio INCRA/UNICAMP, 1998. http://www.eco.unicamp.br/projetos/rurbano/textos/ pesquisa/ fundiaria.html

HOFFMANN, R. Estatística para economistas. 2. ed. São Paulo: Livraria Pioneira Editora. 1991. 426p.

HOFFMANN, R. Estimação da desigualdade dentro de estratos no cálculo do índice de Gini e redundância. Pesquisa e Planejamento Econômico, Rio de Janeiro, v. 9, n. 3, p. 719-738, dez.1979.

INCRA - Instituto Nacional de Colonização e Reforma Agrária. Estatísticas Cadastrais. Recadastramento, 1972. Brasília, Ministério da Agricultura, 1974.

INCRA - Instituto Nacional de Colonização e Reforma Agrária. Estatísticas Cadastrais, 1992. Brasília, Ministério da Agricultura, 1974.

INCRA - Instituto Nacional de Colonização e Reforma Agrária. Estatísticas Cadastrais, 1998. Brasília, Ministério da Agricultura, 1974.

INCRA - Instituto Nacional de Colonização e Reforma Agrária. Estatísticas Cadastrais Anuais, 1991. Brasília, Ministério da Agricultura, 1991.

LEAL, J. A., SERRA, R. V. Petróleo, royalties e região. In: Petróleo, royalties e região (Boletim, ano1, n. 1). UCAM, Campos dos Goytacazes, 2003.

PRADO JR. C. A revolução brasileira. São Paulo: Brasiliense, 1966. 332p.

RANGEL, I. A questão agrária brasileira. Recife: Comissão de Desenvolvimento Econômico de Pernambuco, 1962. 
SAMPAIO, R. A corrida dos votos na terra do petróleo In.: Jornal do Brasil. Ano 113, n. 292, 25 de janeiro de 2004. p. A2.

TOTTI, M. E. F, CARVALHO, A. M., ALTOÉ, A. P. Indicadores de qualidade de vida nas cidades das regiões Norte e Noroeste fluminense. Observatório Socioeconômico da Região Norte e Noroeste Fluminense (Boletim Técnico n. 8). CEFET/NEED, Campos dos Goytacazes, 2002.

TRIBUNAL DE CONTAS DO ESTADO DO RIO DE JANEIRO. Estudos Socioeconômicos dos Municípios do Rio de Janeiro 19972002. http://www.tce.rj.gov.br/sitenovo/index.htm, janeiro de 2004.

\begin{abstract}
The research has as objective to analyze the evolution of the agrarian structure, and the behavior of the economic and social development indicators, for the North and Northwest regions of the Rio de Janeiro state. Moreover, it searchs to verify if the land distribution is an important variable in the explanation of the divergences between the degree of economic development of the cities. The results show that, for the considered regions, the differences in the agrarian structure, separately, can not explain the differences in the degree of economic and social development. The size of the population, in turn, seems to be an important variable in this process. This can be associated to the greater potential demand, what is attractive the private investments. Another reason is, possibly, the greatest politics power, due to the size of the electorate, what can influence in the destination of the public investments.
\end{abstract}

Keywords: agrarian structure, economic and social development, royaltie 